\title{
Specificity of inducible seaweed anti-herbivory defences depends on identity of macroalgae and herbivores
}

\author{
Markus Molis ${ }^{1}$, Jochen Körner ${ }^{2}$, Young Wook Ko ${ }^{3}$, Jeong Ha Kim ${ }^{3, *}$ \\ ${ }^{1}$ Biologische Anstalt Helgoland, Section Seaweed Biology, Alfred Wegener Institute for Polar and Marine Research, \\ Kurpromenade 201, 27498 Helgoland, Germany \\ ${ }^{2}$ Institute for Chemistry and Biology of the Marine Environment (ICBM), Aquatic Ecology, Carl von Ossietzky University, \\ Ammerländer Heerstraße 114-118, 26129 Oldenburg, Germany \\ ${ }^{3}$ Department of Biological Science, Sungkyunkwan University, Suwon 440-746, Republic of Korea
}

\begin{abstract}
Meso-herbivores can strongly affect biomass accrual and macrophytobenthic community structure. To counter grazing effects, constitutive and induced anti-herbivory responses evolved in seaweeds. Feeding-assayed induction experiments were conducted in the laboratory to investigate whether $14 \mathrm{~d}$ grazing periods by either the periwinkle Littorina brevicula or the abalone Haliotis discus induced anti-herbivory defences in the green alga Ulva pertusa and the brown alga Laminaria japonica. Where appropriate, assays were repeated with artificial food containing lipophilic algal extracts, using dichloromethane (DCM) as a solvent, to test whether or not snails induced chemical defences. While exposure to periwinkles reduced palatability of fresh $L$. japonica pieces for naïve conspecific grazers, no such effect was displayed by abalone-exposed L. japonica pieces. Patterns of grazer specificity in the palatability of fresh algae were not confirmed when using artificial food containing algal DCM extracts. This suggests that $L$. japonica either induced morphological defences or periwinkle-deterrent substances originated from the non-lipophilic fraction of defensive chemicals. Grazer-specific induced responses were not apparent in U. pertusa assays. This study revealed that the induction of chemical anti-herbivory responses depends not only on the type of grazer but also on the type of alga on which the grazer feeds.
\end{abstract}

KEY WORDS: Plant-animal interaction $\cdot$ Consumption $\cdot$ Macroalgae $\cdot$ Chemical extracts $\cdot$ Republic of Korea

Resale or republication not permitted without written consent of the publisher

\section{INTRODUCTION}

Herbivores strongly affect biomass accrual of terrestrial and marine plants (Cyr \& Pace 1993) and were experimentally shown to modify the directionality of biodiversity-productivity relationships in marine habitats (Worm et al. 1999, 2002, Hillebrand et al. 2000). Past research on benthic trophic interactions focused on the effects of macro-herbivores (e.g. fishes and urchins) on macroalgae, while knowledge on the ecological effect of the inconspicuous meso-herbivores (e.g. snails, isopods, and amphipods) has only recently emerged (Hay 1996, Duffy \& Hay 2000, Toth et al. 2005, Long et al. 2007, Toth \& Pavia 2007). In contrast to larger grazers, meso-herbivores use macroalgae as habitat as well as for food (Duffy \& Hay 1991), suggesting persistent interactions between mesoherbivores and their prey. In this context, phenotypic plasticity in seaweed responses may represent an important trait in facilitating longer-lasting stable interactions, as macroalgae may tolerate low consumption levels but induce anti-herbivory defences to protect themselves under higher grazing pressure (Karban et al. 1999). 
In contrast to terrestrial systems, where inducible anti-herbivory defences were documented in $>100$ plants (Karban \& Baldwin 1997), this response was detected in <20 seaweed species (Toth \& Pavia 2007). The discrepancy between these 2 systems may result from a research bias. For instance, Toth \& Pavia (2007) documented an exponential increase in the number of macroalgae with inducible defences over the last decade, indicating that these may be more commonly employed in seaweeds than previously suggested. Utilisation of induced defences represents for several reasons a selective advantage for its user over constitutively expressed defences. First, under the assumption that the production of anti-herbivory defences incurs a metabolic cost, permanent expression of antiherbivory defences is detrimental under variable grazing regimes because resources were also allocated to defences at times when they were not needed (Agrawal \& Karban 1999). Second, inducible antiherbivory defences may lower the risk of self-toxicity as harmful compounds were only intermittently present in plant tissues (Agrawal \& Karban 1999). Third, temporarily expressed defences can enhance algal performance by increasing feeding dispersal and reducing average meal size of meso-herbivores (Borell et al. 2004). Less predictable food quality due to inducible defences may be an important driver in the evolution of plant-animal interactions (Hay 1996).

Induction of anti-herbivory defences in macroalgae may depend on the identity of meso-grazers (Amsler 2001). Enzymes from the saliva of the periwinkle Littorina obtusata induced anti-herbivory responses in the fucoid Ascophyllum nodosum (Coleman et al. 2007). Such grazer-associated cues may trigger the evolution of grazer specificity in seaweed responses, but experimental evidence for macroalgae is extremely scarce and controversial. L. obtusata, but not the isopod Idotea granulosa, induced anti-herbivory defences in a European population of the rockweed A. nodosum (Pavia \& Toth 2000), but neither induced antiherbivory defences in a North American population of A. nodosum (Long \& Trussell 2007). Moreover, since the isopod Idotea baltica and the periwinkle Littorina littorea both induced defences in the brown seaweed Fucus vesiculosus (Rohde et al. 2004), different types of feeding modes (radular vs. mandible) cannot fully explain grazer-specific plasticity in seaweed responses. This assumption was indirectly corroborated by Molis et al. (2006), showing grazer specificity in the induction of anti-herbivory responses in the brown seaweed Ecklonia cava for 2 grazer species with similar feeding modes: consumption by the periwinkle Littorina brevicula, but not by the abalone Haliotis discus, reduced the palatability of Ecklonia cava. To date, grazer specificity in the induction of anti-herbivory defences has only been reported for different grazer species on single species of macroalgae. Testing for constancy in grazer-specific patterns among different seaweed species will give more insight into generality and relevance of grazer identity as a driver of trophic interactions between macroalgae and meso-herbivores. The present study features the first formal test on constancy in grazer specificity of induced seaweed responses by asking (1) whether meso-herbivores with similar feeding modes differ in their ability to induce anti-herbivory defences in different seaweed species, (2) whether induced algal responses originate from lipophilic algal substances, and (3) whether induced macroalgae can reduce defences after grazing has ceased.

\section{MATERIALS AND METHODS}

Study organisms. Laminaria japonica Areschoug was introduced to South Korea in the late 1970s. Because this alga does not recruit at Sangju Bay, i.e. the site where grazers were collected, algal specimens used in this study originated from aquaculture facilities at Sangju $\left(34^{\circ} 42^{\prime} \mathrm{N}, 127^{\circ} 59^{\prime} \mathrm{W}\right)$ and Wan Island $\left(34^{\circ} 10^{\prime} \mathrm{N}, 126^{\circ} 37^{\prime} \mathrm{W}\right)$. However, Littorina brevicula commonly co-occurs with $L$. japonica at other sites along the Korean shore (Son \& Hong 1998). The green macroalga Ulva pertusa Kjellman is highly abundant, accumulating in massive mats during summer months on the shore at Sangju, from where it was collected. Pilot studies revealed that 2 snails, the periwinkle L. brevicula Philippi and the abalone Haliotis discus Hannai Ino, readily consumed L. japonica and U. pertusa. Both $U$. pertusa and periwinkles of 8 to $12 \mathrm{~mm}$ diameter were collected in the upper sublittoral at Sangju Bay. Due to intense harvesting, abalone is rare in the field, so $1 \mathrm{yr}$ old $30 \mathrm{~mm}$ long individuals were obtained from the aquaculture facilities of the National Fisheries Research and Development Institute (NFRDI).

Experimental design and setup. Consumer identity (Littorina brevicula and Haliotis discus) and consumption (grazed and ungrazed control) were manipulated in a 2-factorial design to test the ability of grazers to induce anti-herbivory defences in each seaweed species.

An indoor experiment was conducted at the NFRDI, Sangju Bay. Twenty-eight transparent plastic aquaria (vol. 2 l) were placed in each of 2 adjacent ( $<1 \mathrm{~m}$ distance) containers $(2.5 \times 1.5 \times 0.5 \mathrm{~m})$. In each container, Laminaria japonica and Ulva pertusa pieces were randomly allocated to 14 aquaria each (experimental units = EUs) (Fig. 1A). In the first container, 7 of the 14 EUs containing either of the algal species were ran- 


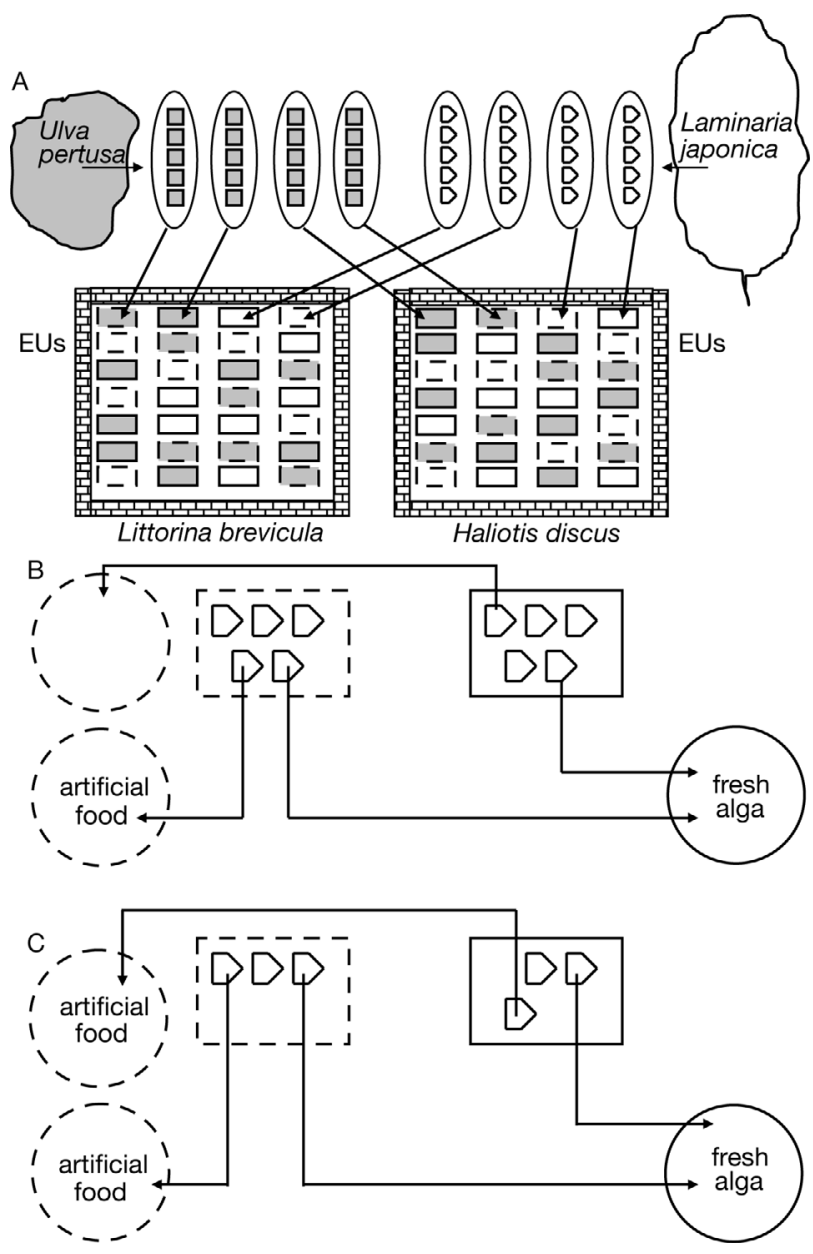

Fig. 1. Experimental setup. (A) Allocation of 20 algal pieces cut from a single specimen of each species of macroalgae Ulva pertusa and Laminaria japonica to experimental units (EUs) in both containers (bricked bars) at the beginning of the experiment. Ovals group algal pieces that were allocated to single EUs. For clarity, allocation of algal pieces to EUs is shown for only 1 of the 7 specimens of each algal species. (B) Principle allocation pattern of algal pieces (only shown for L. japonica pieces and 1 grazer species) for choice-feeding assays using fresh algae or no-choice feeding assays using artificial food at the end of the treatment phase. One of the 3 remaining fresh algal pieces in EUs was used as autogenic control to assess non-feeding related changes in wet mass at the end of the treatment phase. (C) Allocation of algal pieces for feeding assays at the end of the recovery phase. The remaining piece in EUs was used as autogenic control. Use of different algal pieces after the treatment and recovery phase kept data from different phases independent. EUs with solid line $=$ control, EUs with stippled line $=$ with grazers during treatment phase, large solid and stippled circle $=$ feeding arena with choice and no-choice assays, respectively

domly incubated with periwinkles, while the remaining EUs were used as controls. This setup was repeated in the second container, but using Haliotis discus. The non-random arrangement of consumer species in this setup could have affected the feeding behaviour of both snail species. To minimise this possibility, we controlled for temperature, light regime, and water flow, and kept these identical in both containers. The similarity of abiotic conditions in both containers was also reflected by a nonsignificant $(<1 \%)$ difference in growth rates of control algae from both containers ( $t$-test -Laminaria: $t=0.37, \mathrm{p}=0.713$; Ulva: $t=$ $0.68, \mathrm{p}=0.519)$. Filtered (1 $\mu \mathrm{m}$, Micropore) seawater from Sangju Bay flowed unidirectionally $\left(40 \mathrm{ml} \mathrm{min}^{-1}\right.$ ) at a temperature of 18 to $20^{\circ} \mathrm{C}$ through single EUs. Aerated EUs were exposed to ambient irradiance regimes matching nearly ambient photosynthetically active radiation (PAR) intensity at $1 \mathrm{~m}$ water depth (at bottom of aquaria: $85.02 \pm 1.8 \mu \mathrm{mol} \mathrm{s}{ }^{-1} \mathrm{~m}^{-2}$ [mean $\pm \mathrm{SD}$ ], at $1 \mathrm{~m}$ depth in Sangju Bay: $94.98 \pm 3.9 \mu \mathrm{mol} \mathrm{s}^{-1} \mathrm{~m}^{-2}$; Li-Cor underwater quantum sensor LI-192SA).

On 16 June 2003, 7 Laminaria japonica and 7 Ulva pertusa specimens were collected, their macroscopic epibionts removed with a soft sponge, and the algae spun dry in a salad spinner. The same day, 20 pieces were cut from each specimen and evenly allocated to 4 EUs (Fig. 1A). In this way, 5 genetically identical plant pieces (wet mass $3.0 \pm 0.5 \mathrm{~g}$ ) were placed in each of 2 EUs of each container ( 5 pieces per EU $\times 2$ grazing treatments $\times 2$ grazer species $=20$ ). Multiple plant pieces per aquarium were necessary as multiple feeding assays were performed at different times during the $42 \mathrm{~d}$ experiment. Subsequently, plant pieces were cultivated for $14 \mathrm{~d}$ without consumers in the EUs, to allow adaptation to experimental conditions (acclimation phase). Afterwards, half of the EUs with L. japonica and with $U$. pertusa in each container were randomly selected and incubated for $14 \mathrm{~d}$ with 10 Littorina brevicula or 3 Haliotis discus specimens (induction treatment), respectively (Fig. 1A). The second half of the aquaria was left without herbivores (control). At the end of the treatment phase, 2 plant pieces were used from each EU in feeding assays (Fig. 1B) and all grazers were removed. The following recovery phase (14 d) was intended to test for reduction of induced defences after grazing ceased. At the end of the recovery phase, 2 of the remaining 3 algal pieces from each EU were used in feeding assays (Fig. 1C).

Feeding assays. To assess algal palatability at the end of the treatment phase, 1 fresh algal piece was withdrawn from a control EU and offered together with a genetically identical piece withdrawn from a treatment EU to naïve conspecific snails in $72 \mathrm{~h}$ choice-feeding assays (Fig. 1B, Laminaria japonica: $\mathrm{n}=7$; Ulva pertusa: $\mathrm{n}=5$, reduction in replication due to 2 unhealthy algae). Algal pieces were discarded after feeding assays. When significant effects with fresh algae were detected, non-polar compounds were extracted from the second withdrawn algal 
piece of each EU, incorporated into artificial food (see 'Preparation of agar-based food'), and used in nochoice feeding assays (Fig. 1B). The procedure was repeated with different algal pieces withdrawn from EUs after the recovery phase (Fig. 1C). All feeding assays were performed with 10 Littorina brevicula or 3 Haliotis discus, contained within $300 \mathrm{ml}$ seawater in feeding arenas made of transparent plastic Petri dishes $(\varnothing 15 \mathrm{~cm}, 3 \mathrm{~cm}$ height). Feeding assays were run at the NFRDI in a constant-temperature room set to $19^{\circ} \mathrm{C}$. Water in feeding arenas was exchanged every $12 \mathrm{~h}$. No-choice assays with artificial food items were necessary to allocate non-grazing-related dislodgement of agar pieces unambiguously to original food items. To obtain the total mass of artificial feed at the end of feeding assays, seawater containing dislodged food parts was poured onto paper filters, retained food weighed to the nearest $\mathrm{mg}$, and this mass added to that of the food item remaining in the feeding arena at the end of the feeding assay. Consumption was measured to determine algal palatability by weighing food items at the beginning and end of feeding assays. Additional pieces of fresh and artificial food were transferred into feeding arenas without grazers to assess autogenic mass changes during feeding assays (Peterson \& Renaud 1989). Autogenic control and assayed alga stemmed from the same EU, i.e. they had identical experimental grazing histories and genomes. Actual consumption during feeding assays was calculated as:

$$
F_{\mathrm{b}} \times\left(C_{\mathrm{e}} \times C_{\mathrm{b}}{ }^{-1}\right)-F_{\mathrm{e}}
$$

where $F$ and $C$ indicate wet mass of the food item and the autogenic control, respectively, and the subscripts $\mathrm{b}$ and e indicate measurements at the beginning and end of feeding assays, respectively.

Preparation of agar-based food. Non-polar crude extracts were obtained by submerging individual algal pieces in $10 \mathrm{ml}$ dichloromethane (DCM). After a $24 \mathrm{~h}$ extraction period at room temperature, extracts were poured onto $3 \mathrm{~g}$ of powdered Ulva lactuca to standardise artificial feed quality (Deal et al. 2003). During the next $12 \mathrm{~h}$, evaporation of DCM was accomplished at room temperature under a hood, prior to embedding extract-coated Ulva lactuca into agar. Two feeds were processed from single algal pieces, according to the methods of Hay et al. (1994) and were used as the assayed food and its autogenic control.

Statistical analysis. Consumption rates of fresh algae (choice assays) after treatment and recovery phases were separately analysed for each phase and algal species by 2-factorial repeated-measures ANOVA with consumption of treated versus control piece from 1 feeding assay as the repeated measure (2 levels, fixed) and consumer species as the grouping factor
(2 levels, fixed). Thus, algal pieces that were used after the treatment and recovery phase lacked independence as they originated from the same EU. Because there were only 2 treatments, testing for sphericity was not relevant (Quinn \& Keough 2002). Due to ambiguous selection of an appropriate error term for post-hoc tests involving within-subject by between-group interactions (Winer et al. 1991), 1-tailed paired $t$-tests were performed as alternative post-hoc tests for each grazer species separately, after confirming normality of differences by the Kolmogorov-Smirnov test. Consumption rates of artificial food (no-choice assays) after treatment and recovery phases were separately analysed for each phase and algal species by a $2 \times 2$-factorial ANOVA with grazer species ( 2 levels, fixed) and consumption (2 levels, fixed) as main factors. Homogeneity of variances was tested with Levene's test and, where appropriate, data were log-transformed to meet the assumptions. Tukey's HSD was used as a post-hoc test.

\section{RESULTS}

\section{Fresh algae}

\section{Laminaria japonica}

Non-feeding related changes in Laminaria japonica wet mass indicated minimal biomass losses of $1.5 \pm$ $0.023 \%$ (mean $\pm \mathrm{SD}$ ) during the entire experiment, with highest and lowest reductions during the acclimation phase $(3 \pm 0.034 \%)$ and recovery phase $(0.1 \pm$ $0.003 \%)$, respectively.

At the end of the treatment phase, changes in Laminaria japonica consumption following snail exposure were grazer-specific, as indicated by a significant consumer $\times$ grazing interaction (Table 1). Exposure to grazers reduced consumption rates on $L$. japonica relative to controls significantly when Littorina brevicula was used (paired $t$-test: $t_{6}=4.21, \mathrm{p}=0.006$ ) but not with Haliotis discus (paired $t$-test: $t_{6}=1.79, \mathrm{p}=0.125$ ). Control $L$. japonica were consumed on average 5.7 times more heavily than $L$. brevicula-exposed conspecifics (Fig. 2A). This effect was strong enough to produce a significant overall consumption effect (Table 1), in which control specimens of $L$. japonica were consumed on average (when pooled from $L$. brevicula and $H$. discus assays) 2-fold more than grazed conspecifics (Fig. 2A).

At the end of the recovery phase, no significant differences in consumption were detected (Table 1). However, in Haliotis discus assays, control algae were a non-significant 6 times more preferred than $H$. discus-exposed Laminaria japonica (paired $t$-test: $t_{6}=$ 
1.65, $p=0.075$ ), while mean difference in consumption between control specimens and Littorina breviculaexposed L. japonica was $<20 \%$ (Fig. 2B).

\section{Ulva pertusa}

A non-significant consumer $\times$ grazing interaction in assays with fresh Ulva pertusa specimens indicated that the amount of consumed U. pertusa biomass was independent of grazer identity (Table 1). In contrast to the results with Laminaria japonica, Littorina brevicula-exposed U. pertusa pieces tended to stimulate consumption of $U$. pertusa by naïve conspecific snails (Fig. 3). Interestingly, the negative consumption values of Haliotis discus-grazed $U$. pertusa pieces indicate that $U$. pertusa pieces were gaining more biomass in the presence of grazers than did conspecifics in grazerfree EUs. Due to an absence of induction of antiherbivory defences in $U$. pertusa, no assays were conducted at the end of its recovery phase.

\section{Algal extracts (only Laminaria japonica)}

At the end of the treatment phase, consumption of agar-based food containing non-polar Laminaria japonica extracts (Fig. 4A,B) was on average more than 5 times higher than in assays using fresh algae (Fig. 2A,B). At the end of the treatment phase, no significant main or interactive effects were detected (Table 2), although trends between assays using $L$.

Table 1. Fresh Laminaria japonica $(n=7)$ and Ulva pertusa $(n=5)$. Results of repeated-measures ANOVA, comparing the effects of herbivore species (Littorina brevicula and Haliotis discus) and grazing (exposed to grazers and controls) on consumption of intact seaweeds immediately (treatment phase) and $14 \mathrm{~d}$ after grazing ceased (recovery phase, only L. japonica). Consumption was assessed during $72 \mathrm{~h}$ choice-feeding assays using either 10 or 3 individuals of $L$. brevicula or $H$. discus, respectively

\begin{tabular}{|c|c|c|c|c|c|c|c|c|}
\hline \multirow[t]{2}{*}{ Source } & \multicolumn{4}{|c|}{ — Laminaria japonica — } & \multirow{2}{*}{$\overline{\mathrm{df}}$} & \multicolumn{2}{|c|}{ Ulva pertusa } & \multirow[b]{2}{*}{$\mathrm{p}$} \\
\hline & $\mathrm{df}$ & MS & $F$ & $\mathrm{p}$ & & MS & $F$ & \\
\hline \multicolumn{9}{|c|}{ Treatment phase } \\
\hline Consumer (C) & 1 & 0.008 & 2.09 & 0.174 & 1 & 0.199 & 5.06 & 0.055 \\
\hline Residual & 12 & 0.004 & & & 8 & 0.039 & & \\
\hline Grazing (G) & 1 & 0.026 & 10.87 & 0.006 & 1 & 0.001 & 0.02 & 0.900 \\
\hline $\mathrm{C} \times \mathrm{G}$ & 1 & 0.050 & 20.90 & 0.001 & 1 & 0.191 & 2.82 & 0.132 \\
\hline Residual & 12 & 0.002 & & & 8 & 0.068 & & \\
\hline \multicolumn{9}{|l|}{ Recovery phase } \\
\hline Consumer (C) & 1 & 0.042 & 1.69 & 0.219 & & & & \\
\hline Residual & 12 & 0.025 & & & & & & \\
\hline Grazing (G) & 1 & 0.073 & 1.99 & 0.184 & & & & \\
\hline $\mathrm{C} \times \mathrm{G}$ & 1 & 0.106 & 2.90 & 0.115 & & & & \\
\hline Residual & 12 & 0.037 & & & & & & \\
\hline
\end{tabular}

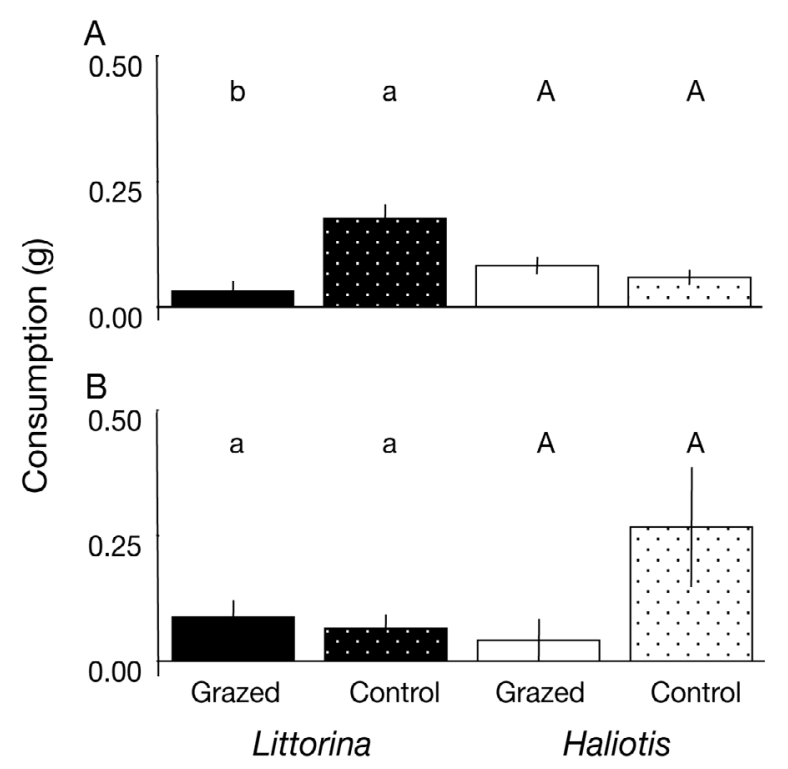

Fig. 2. Fresh Laminaria japonica. Mean $( \pm \mathrm{SE})$ consumption of periwinkles Littorina brevicula and abalone Haliotis discus determined in $72 \mathrm{~h}$ choice-feeding assays at the end of the (A) treatment and (B) recovery phase. Treatments sharing lowercase ( $L$. brevicula assays) or uppercase ( $H$. discus assays) letters are not significantly different, as tested with paired $t$-tests $(n=7)$. Grazed: snail exposure during the treatment phase; Control: absence of snails during the treatment phase

japonica extracts and fresh conspecifics were remarkably similar (Figs. 2A vs. 4A \& 2B vs. 4B).

At the end of the recovery phase, no significant differences were detected by the overall analysis (Table 2). Consumption rates on artificial food from control plants were almost identical in magnitude between the treatment and the recovery phase, indicating that the palatability of non-polar extracts of control specimens of Laminaria japonica was nearly constant over the course of the experiment.

\section{DISCUSSION}

The present study revealed that grazing by meso-herbivores changed the level of palatability in algae but that induced responses were grazer-specific and also dependent on the type of alga. Missing effects in assays using nonpolar Laminaria japonica extracts suggest that the grazer-induced regulation of palatability in this seaweed species was not triggered by lipophilic compounds. 


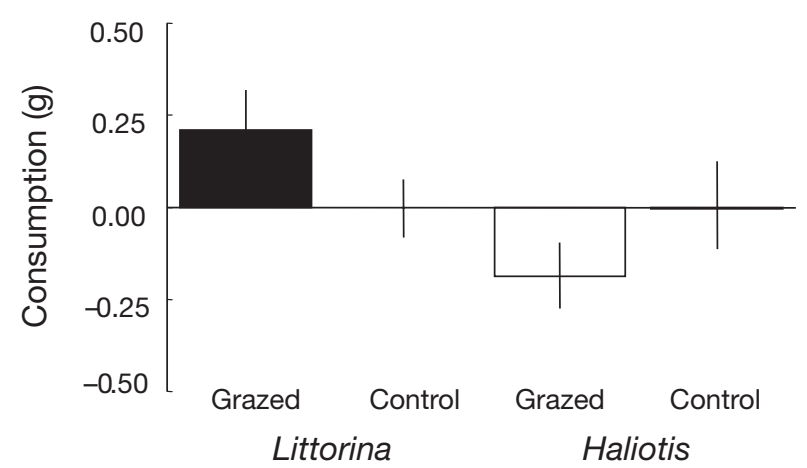

Fig. 3. Fresh Ulva pertusa. Mean $( \pm \mathrm{SE})$ consumption of periwinkles Littorina brevicula and abalone Haliotis discus at the end of the treatment phase $(n=5)$. Assay conditions, analysis, symbols, and their interpretation as in Fig. 2

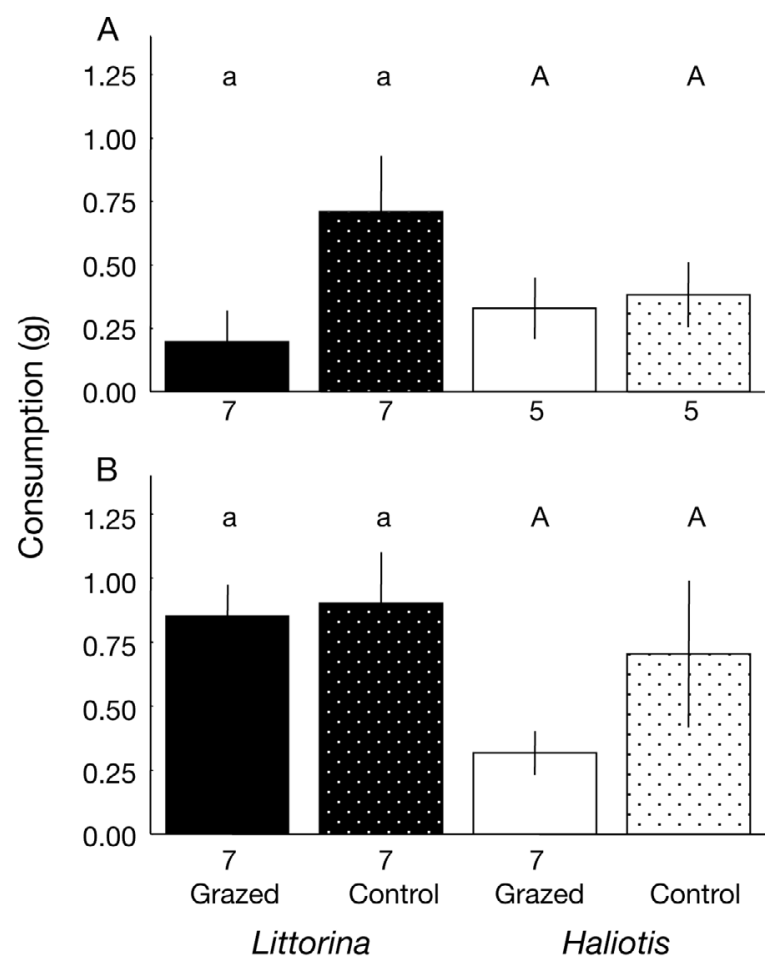

Fig. 4. Laminaria japonica. Agar-based food containing nonpolar L. japonica extracts. Mean $( \pm \mathrm{SE})$ consumption of periwinkles Littorina brevicula and abalone Haliotis discus determined in $72 \mathrm{~h}$ no-choice feeding assays at the end of the (A) treatment and (B) recovery phase. Numbers under bars indicate sample sizes. Treatments sharing lowercase $(L$. brevicula assays) or uppercase ( $H$. discus assays) letters are not significantly different, as tested with $2 \times 2$ ANOVA

\section{Induction of chemical anti-herbivory defences}

The observed lower palatability of previously Littorina brevicula-attacked fresh Laminaria japonica pieces compared to ungrazed (control) conspecifics, and the disappearance of differences in palatability
Table 2. Laminaria japonica. Artificial food containing nonpolar extracts of $L$. japonica. Results of $2 \times 2$ ANOVA, comparing the effects of the herbivores Littorina brevicula $(\mathrm{n}=7)$ and Haliotis discus ( $\mathrm{n}=5$ and 7 after treatment and recovery phase, respectively) and grazing (exposed to grazers and controls) on consumption of agar-based food containing nonpolar extracts of $L$. japonica immediately (treatment phase) and $14 \mathrm{~d}$ after exposure to grazers ceased (recovery phase). Consumption was assessed during $72 \mathrm{~h}$ no-choice feeding assays using either 10 or 3 individuals of $L$. brevicula or H. discus, respectively

\begin{tabular}{|lrccc|}
\hline Source & df & MS & $F$ & $p$ \\
\hline Treatment phase & & & & \\
Consumer (C) & 1 & 0.057 & 0.35 & 0.562 \\
Grazing (G) & 1 & 0.469 & 2.88 & 0.106 \\
C $\times$ G & 1 & 0.307 & 1.88 & 0.185 \\
Residual & 20 & 0.163 & & \\
Recovery phase & & & & \\
Consumer (C) & 1 & 0.944 & 3.75 & 0.065 \\
Grazing (G) & 1 & 0.334 & 1.33 & 0.260 \\
C $\times$ G & 1 & 0.199 & 0.79 & 0.383 \\
Residual & 24 & 0.251 & & \\
\hline
\end{tabular}

after grazing ceased, may result from either preferential feeding of littorinid snails or, alternatively, from an induction of anti-herbivory defences. Preferential consumption should have removed the most palatable L. japonica tissues during the treatment phase in grazer-exposed but not in control EUs. Consequently, control pieces would have been more consumed than simultaneously offered grazer-exposed L. japonica pieces. In the same sense, diminishing differences in palatability between control and periwinkle-exposed L. japonica pieces after grazing ceased, i.e. at the end of the recovery phase, could be explained by new growth of palatable tissues in previously grazed algae during recovery. However, wet mass measurements of autogenic control pieces failed to show such a growth response. The detected slight decrease in L. japonica biomass during the recovery phase indicates that preferential consumption cannot explain observed changes in L. japonica palatability during the experiment. Alternatively, the observed changes in palatability could have resulted from an induction of antiherbivory defences. This conclusion is supported by the fact that littorinid snails consumed $<15 \%$ of L. japonica biomass during the treatment phase. This value corresponds well with other observations of the effect of meso-grazing on algal biomass (Klumpp \& Pulfrich 1989) and suggests that sufficient palatable tissue was available to meso-grazers throughout feeding assays after the treatment and recovery phase. Furthermore, feeding scars were scattered over the entire area of the L. japonica pieces. Preferential consumption, however, would more likely result in localised 
rather than dispersed feeding activities across the algal thallus. Finally, feeding assays using agar-based feed of lipophilic L. japonica extracts produced similar patterns as detected with fresh algae. However, missing main and interactive effects between grazing treatments and consumer species indicate that grazing did not induce the production of repulsive lipophilic substances in either of the 2 tested species of macroalgae. To our knowledge, no study has characterised and identified induced chemicals that deter herbivores, while a few experiments have tested grazer deterrent effects of crude lipophilic algal extracts (Weidner et al. 2004, Ceh et al. 2005, Macaya et al. 2005, Rothäusler et al. 2005, Diaz et al. 2006). Only in the brown alga Sargassum asperifolium was an observed induction of anti-herbivory defence confirmed when lipophilic extracts were used (Ceh et al. 2005). Thus, induced defences in macroalgae most likely originate from either the non-lipophilic fraction of macroalgal secondary substances or from morphological changes (Van Alstyne 1989).

\section{Grazer specificity of induced anti-herbivory responses}

Grazing periwinkles, but not abalone, induced anti-herbivory defences in Laminaria japonica. The absence of an induced response by Haliotis discus possibly resulted from its higher tolerance against grazingdeterrent compounds compared to Littorina brevicula. Alternatively, anti-herbivory defences against $H$. discus grazing were employed constitutively. To obtain a more complete picture of the potential inductive role of abalone, abalone-exposed macroalgae should be offered in future experiments to $L$. brevicula, similar to the experiments conducted by Long et al. (2007). Missing effects on $L$. brevicula grazing in these assays would give additional evidence that abalone may not induce antiherbivory defences.

Existing knowledge on grazer-specific induced antiherbivory defences in macroalgae is extremely scarce. Pavia \& Toth (2000) reported induced anti-herbivore defences in Ascophyllum nodosum against grazing periwinkles Littorina obtusata but not against the isopod Idotea granulosa. The authors suggested that differences in grazing damage may put L. obtusataexposed $A$. nodosum individuals at a higher risk of losing more biomass than I. granulosa-grazed conspecifics, due to the more localised feeding mode of periwinkles, perhaps due to the slow movement of snails. Thus, for macroalgae, snail-associated traits could be highly predictable cues to strong grazing effect. If radular grazing caused different mechanical cues than mandible grazing, A. nodosum could possi- bly distinguish between snails and isopods, and thus determine the potential risk of losing biomass. Under this assumption, macroalgae should display similar anti-herbivory responses when exposed to grazers with similar feeding modes, which is clearly not the case in the present study. However, little is known about the ecological consequences of different radular morphologies (Padilla 2004). Differences in radular morphology between Littorina brevicula and Haliotis discus were possibly large enough to provoke a differential defensive response in Laminaria japonica. Alternatively, the induction of anti-herbivory defences in algae may not be cued by mechanical stimuli of the feeding apparatus alone. This possibility is corroborated by Rohde et al. (2004), who showed that 2 grazer species with different feeding apparatus both induced anti-herbivory defences in the fucoid Fucus vesiculosus. Moreover, simulated grazing (clipping treatments) did not induce anti-herbivory defences in F. vesiculosus (Rohde et al. 2004), demonstrating the ineffectiveness of solely mechanically damaged macroalgal tissues to induce anti-herbivory defences. Coleman et al. (2007) gave the first experimental evidence that chemical grazer cues induced anti-herbivory defences. Thus, a combination of mechanical and chemical cues might be required to induce anti-herbivory defences in L. japonica. Combining feeding-related mechanical and chemical grazing cues may be one way of matching deterrent responses with actual herbivore load and thus optimising defences. For instance, mechanical cues alone bear a risk of confounding non-grazingrelated biomass loss in wave-battered seaweeds with attacking herbivores (Amsler 2001). Future experiments aiming to tease apart the role of separate or combined mechanical and chemical grazer cues may be important for a better understanding of grazer specificity in induced seaweed responses. Preferably, these experiments should also be conducted in the field to include additional environmental factors that may affect the outcome of species interactions.

\section{Grazer specificity depends on seaweed identity}

Grazer specificity of induced chemical antiherbivory defences could be documented in Laminaria japonica, but not in Ulva pertusa. This suggests that besides grazer identity, seaweed-specific traits also determine whether or not repulsive responses are induced. Grazing by abalone stimulated growth in $U$. pertusa. Therefore, U. pertusa used an opposite mechanism to cope with herbivory than $L$. japonica. The latter reduced the effect of herbivores, while $U$. pertusa showed compensatory biomass accrual. However, Toth (2007) reported the presence of 
inducible anti-herbivory defences in Ulva lactuca after exposure to the isopod Idotea granulosa. Consequently, different life history traits among Laminaria and Ulva may explain opposing responses to herbivory only to a certain extent. Tolerance to herbivory has evolved as one survival strategy in macroalgae with sheet-like thallus forms (Littler \& Litter 1980), e.g. Ulva. Besides thallus structure, growth has been suggested as an additional algal trait for differential responses to herbivores (Steneck \& Dethier 1994). Fast-growing macroalgae, e.g. Ulva spp., have been reported to escape consumption, while slowergrowing seaweeds, e.g. L. japonica in the present study, may optimise their fitness by deterring grazers (Cronin 2001).

Molis et al. (2006) documented grazer-specific inducible anti-herbivory responses in the brown seaweed Ecklonia cava that matched those shown in the present study for Laminaria japonica. The consistency of patterns in both kelp species compared to the contrasting pattern in Ulva pertusa shows that grazer specificity in macroalgal defences may be linked to seaweed taxonomy. Evaluating grazer specificity in macroalgae over a range from closely to remotely related species of macroalgae may improve the predictability of grazer specificity in induced responses and may allow more insight into the variability of algal traits that have potential ecological implications on the structure of food chains (Agrawal 2001, Long et al. 2007) and the level of herbivore fitness (Toth et al. 2005).

Acknowledgements. We are grateful to NFRDI staff for provision of grazers. Experiments carried out in Sangju Bay were supported by grant KRF 2002-070-C00088 to J.H.K. Funding by Stifung Mercartor is acknowledged. We thank John Griffin and Robert de Wreede for proofreading. Comments by 3 anonymous reviewers greatly improved the quality of this manuscript.

\section{LITERATURE CITED}

Agrawal AA (2001) Phenotypic plasticity in the interactions and evolution of species. Science 294:321-326

Agrawal AA, Karban R (1999) Why induced defenses may be favored over constitutive strategies in plants. In: Tollrian R, Harvell CD (eds) The ecology and evolution of inducible defenses. Princeton Press, Chichester, p 45-61

Amsler CD (2001) Induced defenses in macroalgae: the herbivore makes a difference. J Phycol 37:353-356

Borell EM, Foggo A, Coleman RA (2004) Induced resistance in intertidal macroalgae modifies feeding behaviour of herbivorous snails. Oecologia 140:328-334

Ceh J, Molis M, Dzeha TM, Wahl M (2005) Induction and reduction of anti-herbivore defenses in brown and red macroalgae off the Kenyan coast. J Phycol 41:726-731

Coleman RA, Ramchunder SJ, Moody AJ, Foggo A (2007) An enzyme in snail saliva induces herbivore-resistance in a marine alga. Funct Ecol 21:101-106
Cronin G (2001) Resource allocation in seaweeds and marine invertebrates: chemical defense patterns in relation to defense theories. In: McClintock JB, Baker BJ (eds) Marine chemical ecology. CRC Press, New York, p 325-353

Cyr H, Pace ML (1993) Magnitude and patterns of herbivory in aquatic and terrestrial ecosystems. Nature 361:148-150

Deal MS, Hay ME, Wilson D, Fenical W (2003) Galactolipids rather than phlorotannins as herbivore deterrents in the brown seaweed Fucus vesiculosus. Oecologia 136: 107-114

Diaz E, Guldenzoph C, Molis M, McQuaid C, Wahl M (2006) Variability in grazer-mediated defensive responses of green and red macroalgae on the south coast of South Africa. Mar Biol 149:1301-1311

Duffy JE, Hay ME (1991) Food and shelter as determinants of food choice by an herbivorous marine amphipod. Ecology 72:1286-1298

Duffy JE, Hay ME (2000) Strong impacts of grazing amphipods on the organization of a benthic community. Ecol Monogr 70:237-263

Hay ME (1996) Marine chemical ecology: What's known and what's next? J Exp Mar Biol Ecol 200:103-134

Hay ME, Kappel QE, Fenical W (1994) Synergisms in plant defenses against herbivores: interactions of chemistry, calcification, and plant quality. Ecology 75:1714-1726

Hillebrand H, Worm B, Lotze HK (2000) Marine microbenthic community structure regulated by nitrogen loading and grazing pressure. Mar Ecol Prog Ser 204:27-38

Karban R, Baldwin IT (1997) Induced responses to herbivory. University of Chicago Press, Chicago, IL

Karban R, Agrawal AA, Thaler JS, Adler LS (1999) Induced plant responses and information content about risk of herbivory. Trends Ecol Evol 14:443-447

Klumpp DW, Pulfrich A (1989) Trophic significance of herbivorous macroinvertebrates on the central Great Barrier Reef. Coral Reefs 8:135-145

Littler MM, Littler DS (1980) The evolution of thallus form and survival strategies in benthic marine macroalgae: field and laboratory tests of a functional form model. Am Nat 116:25-44

Long JD, Trussell GC (2007) Geographic variation in seaweed induced responses to herbivory. Mar Ecol Prog Ser 333: $75-80$

Long JD, Hamilton RS, Mitchell JL (2007) Asymmetric competition via induced resistance: specialist herbivores indirectly suppress generalist preference and populations. Ecology 88:1232-1240

Macaya EC, Rothausler E, Thiel M, Molis M, Wahl M (2005) Induction of defenses and within-alga variation of palatability in two brown algae from the northern-central coast of Chile: effects of mesograzers and UV radiation. J Exp Mar Biol Ecol 325:214-227

Molis M, Körner J, Ko YW, Kim JH, Wahl M (2006) Inducible responses in the brown seaweed Ecklonia cava: the role of grazer identity and season. J Ecol 94:243-249

Padilla DK (2004) Form and function of radular teeth of herbivorous molluscs: focus on the future. Am Malacol Bull 18:163-168

Pavia H, Toth GB (2000) Inducible chemical resistance to herbivory in the brown seaweed Ascophyllum nodosum. Ecology 81:3212-3225

Peterson CH, Renaud PE (1989) Analysis of feeding preference experiments. Oecologia 80:82-86

Quinn GP, Keough MJ (2002) Experimental design and data analysis for biologists. University Press, Cambridge

Rohde S, Molis M, Wahl M (2004) Regulation of anti- 
herbivore defence by Fucus vesiculosus in response to various cues. J Ecol 92:1011-1018

Rothäusler E, Macaya EC, Molis M, Wahl M, Thiel M (2005) Laboratory experiments examining inducible defense show variable responses of temperate brown and red macroalgae. Rev Chil Hist Nat 78:603-614

Son MH, Hong SY (1998) Reproduction of Littorina brevicula in Korean waters. Mar Ecol Prog Ser 172:215-223

Steneck RS, Dethier MN (1994) A functional group approach to the structure of algal-dominated communities. Oikos 69:476-498

Toth GB (2007) Screening for induced herbivore resistance in Swedish intertidal seaweeds. Mar Biol 151:1597-1604

Toth GB, Pavia H (2007) Induced herbivore resistance in seaweeds: a meta-analysis. J Ecol 95:425-434

Toth GB, Langhamer O, Pavia H (2005) Inducible and constitutive defenses of valuable seaweed tissues: conse-

Editorial responsibility: Howard Browman, Storebø, Norway quences for herbivore fitness. Ecology 86:612-618

Van Alstyne KL (1989) Adventitious branching as a herbivore-induced defense in the intertidal brown alga Fucus distichus. Mar Ecol Prog Ser 56:169-176

Weidner K, Lages BG, da Gama BAP, Molis M, Wahl M, Pereira RC (2004) Effects of mesograzers and nutrient levels on the induction of defenses in several Brazilian macroalgae. Mar Ecol Prog Ser 283:113-125

Winer BJ, Brown DR, Michels KM (1991) Statistical principles in experimental design. McGraw-Hill, New York

Worm B, Lotze HK, Bostrom C, Engkvist R, Labanauskas V, Sommer U (1999) Marine diversity shift linked to interactions among grazers, nutrients and propagule banks. Mar Ecol Prog Ser 185:309-314

Worm B, Lotze HK, Hillebrand H, Sommer U (2002) Consumer versus resource control of species diversity and ecosystem functioning. Nature 417:848-851

Submitted: April 17, 2007; Accepted: September 17, 2007 Proofs received from author(s): January 29, 2008 